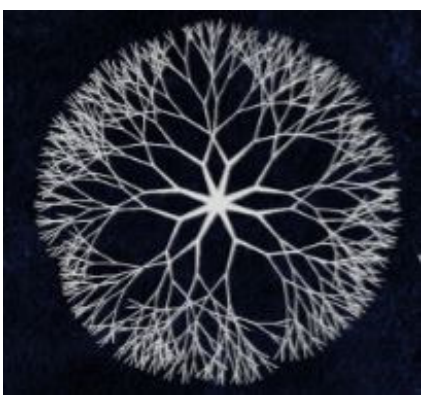

Khronos, Revista de História da Ciência

ISSN 2447-2158 - no 4, agosto 2017

DOSSIÊ - História das Ciências e seu papel na educação básica brasileira

\title{
A História da Física e a Física Escolar: incoerências entre a ciência e o ensino
}

\author{
Renato Marcon Pugliese \\ Doutor em Educacão - FE-USP \\ renato.pugliese@ifsp.edu.br
}

Recebido em 13/06/2017. Aprovado em 10/08/2017.

Como citar este artigo: Pugliese, R. M.; "A história da física e a física escolar: incoerências entre a ciência e o ensino". Khronos, Revista de História da Ciência, nº4, p. 32-44. 2017. Disponível em <http://revistas.usp.br/khronos>. Acesso em dd/mm/aaaa.

Resumo: Este trabalho compara como a história da física apresenta um ramo da ciência permeado de conflitos, construído em contextos sociais, políticos, econômicos e religiosos bastante característicos, e como a física ensinada nas escolas básicas parece apresentada como o oposto da epistemologia. Usamos como referenciais teóricos historiadores e sociólogos da ciência, epistemólogos, físicos e professores de física. Como metodologia de pesquisa, aplicamos um questionário sobre ciência e ensino de física a professores regulares no ensino médio. Concluímos que a física ensinada nas escolas, apesar das inúmeras reformas e propostas curriculares, continua distante da física enquanto ciência e cultura.

Palavras-chave: ensino de física, história da ciência, trabalho docente.

\section{The History of Physics and Physics in School: inconsistencies between science and teaching}

\begin{abstract}
This paper compares how the history of physics presents a branch of science permeated by conflict, constructed in very characteristic social, political, economic and religious contexts, and how physics taught in basic schools seems to be presented as the opposite of epistemology. We use as theoretical references historians and sociologists of science, epidemiologists, physicists and physics teachers. As a research methodology, we applied a questionnaire about science and physics teaching to regular teachers in high school. We conclude that the physics taught in schools, despite the numerous reforms and curricular proposals, remains distant from physics as a science and culture.
\end{abstract}

Keywords: physics teaching, history of science, teaching work. 


\section{Apresentação}

No âmbito de contribuir para a discussão sobre a História das Ciências e o seu papel na educação básica brasileira, é apresentado um texto que versa sobre como a história da física oferece uma série de informações que nos permitem analisar a construção do que entendemos hoje a física como ciência, no escopo epistemológico, e como a prática do ensino da física nas escolas brasileiras está desvinculada de sua realidade histórica. Este texto foi escrito com base em dados de pesquisas anteriores, devidamente recortado e adaptado para esta publicação. ${ }^{1}$

Primeiramente serão trabalhados os aspectos gerais do que entendemos hoje como física: ciência, cultura e epistemologia. Adiante, serão apresentados dados sobre a física ensinada na rede pública de ensino na cidade de São Paulo, a partir do estudo de questionários aplicados a professores das redes municipal, estadual e federal. Por fim, será feita uma análise da estrutura de ensino da física, quando comparada à ótica de sua história.

\section{A Física como ciência e cultura na História}

A ciência é uma atividade humana que vem sendo construída ao longo dos últimos milênios e que possui uma série de características bastante específicas, comparativamente às outras atividades humanas como a arte, a prática religiosa, a meditação e o esporte, tais como: a observação sistemática da natureza, de seus fenômenos, seus sujeitos e objetos; a análise e o estudo dessas observações; a categorização de aspectos comuns, diferentes e opostos, envolvendo temas materiais e não materiais; a construção e a reconstrução da história; a previsão de fenômenos, processos e comportamentos naturais (humanos ou não) e culturais, entre outros. Para Alan Isaacs e Valerie Pitt, "no momento em que [o ser humano] começou a perceber que certos efeitos se seguiam sempre a uma determinada causa, nasceu o estudo sistemático da natureza, ao qual chamamos ciência". ${ }^{2}$

Atualmente, qualquer sociedade faz uso de resultados das pesquisas em ciências, seja no uso da eletricidade, de transportes, da vacinação, etc., além do que a ciência no século XX proporcionou um prestígio para os cientistas que nunca havia acontecido, com verbas para pesquisas e projetos, especialmente em física nuclear e astrofísica, áreas que usaram e abusaram dos recursos no âmbito da Guerra Fria, por exemplo. ${ }^{3}$ Contudo, no final do século XX, a física torna a voltar sua produção quase que exclusivamente à academia. ${ }^{4}$

O modo como a física funciona, essa forma de olhar para o mundo, essa filosofia sistemática, aparentemente surgiu com os gregos alguns séculos antes da Era Cristã e permitiu que o homem abrisse, por vezes em pequenos grupos, espaço para compreender diversos

1 PUGLIESE, R. M. Consumindo a Física na escola básica: a sociedade do espetáculo e as novas propostas curriculares. Dissertação de Mestrado, FEUSP, IFUSP, São Paulo, 2011. Disponível em http://www.teses.usp.br/teses/disponiveis/81/81131/tde-31052012-103258/pt-br.php; PUGLIESE, R. M. O Trabalho do Professor de Física no Ensino Médio: realidade, vontade e necessidade. Tese de Doutorado, FEUSP, São Paulo, 2016. Disponível em

http://www.teses.usp.br/teses/disponiveis/48/48134/tde-06102016-153449/pt-br.php

2 ISAACS, Alan e PITT, Valerie. Física. Trad. Maria P. B. De M. Charlier e René F. J. Charlier. São Paulo: Edições Melhoramentos, 1976, p. 6.

3 MENEZES, Luis Carlos de. A Matéria - uma aventura do espírito: fundamentos e fronteiras do conhecimento físico. São Paulo: Editora Livraria da Física, 2005.

4 HAMBURGER, Ernest W. O que é física. São Paulo: Editora Brasiliense, 6a ed., 1992. 
fenômenos naturais, situações, processos e comportamentos que anteriormente não lhe era possível compreender. ${ }^{5}$

Para entender o que caracteriza a física (e as ciências naturais), podemos avaliar interpretações como a do físico norte-americano Richard Feynman, para quem "a matemática não é uma ciência de nosso ponto de vista, no sentido de que não é uma ciência natural. O teste de sua validade não é a experiência". ${ }^{6}$

De acordo com o professor Luís Carlos de Menezes, "a palavra física, do grego physiké, tem origem em physis, expressão grega para natureza, no sentido de realidade natural sensível". 7 O termo em questão está relacionado à natureza material, corpórea, que pode ser sentida, e que seria o oposto à metafísica, ou seja, ao que não pode ser sentido.

Estas simples definições nos permitem perceber que o estudo da física está diretamente ligado à observação da natureza, sensível ao homem, no espaço e no tempo, bem como a compreensão de como era ou do que houve com a natureza anterior, no caso do tempo, ou em outros locais, no caso do espaço, onde o homem não esteve. Também permite prever o que será e como será a natureza posterior ao homem, no tempo, e em lugares ainda não mensuráveis, no espaço. Essa observação, aliada ao registro, ao compartilhamento de dados e ideias, à análise sistemática utilizando recursos, ferramentas e conhecimentos prévios e aos problemas que se pretendem compreender, forma o que chamamos hoje de física.

Para o físico e ensaísta francês Lévy-Leblond, os cientistas estão a todo instante criando mundos imaginários (ficção), como forma de argumentar sobre fatos (mundo real) observados: estudam-se modelos ideais para entender o mundo real. ${ }^{8}$

Nesse tortuoso caminho, ao longo dos séculos, muitas teorias e conceitos físicos foram desenvolvidos (a física enquanto ciência), bem como muitas teorias e conceitos sobre como a física se faz (a epistemologia e a filosofia da ciência) e, não por menos, muitas teorias e conceitos estão surgindo sobre ensinar e aprender física (o ensino de física enquanto ciência).

Durante a expansão do islamismo e a ocupação de diversas regiões entre os séculos VII e XII, especialmente nas cidades onde anteriormente houvera domínio grego, muitos textos foram traduzidos e os muçulmanos passaram a desenvolver ciência de maneira rica e fundamental para a física atual. Na matemática, temos o advento da álgebra, da numeração árabe (e do zero), a trigonometria, a aritmética e a análise combinatória; na física (e na astronomia), a percepção de leis universais, o estudo da óptica, os calendários precisos; isso sem contar com os avanços na medicina e nas artes. ${ }^{?}$

Para o professor Roshdi Rashed, a gênese das principais características da matemática desenvolvida pelos árabes, e fundamental para a evolução da física, está em Bagdá no começo do século IX, especialmente nos trabalhos de Muhammad al-Khwarizmi, onde surge a álgebra como campo independente na matemática, permitindo a percepção de que há diversas formas de se trabalhar com os números e as instrumentações. Essa nova matemática foi fundamental para a evolução tão intensa da física nos séculos seguintes. No entanto, não podemos deixar de

5 SCHENBERG, Mário. Pensando a física. São Paulo: Landy Editora, 2001; ZANETIC, João. FMT 405 Evolução dos conceitos da física. $1^{\text {a }}$ parte: Alguns tópicos de "fillosofia" da ciência. Notas de aula $1^{\circ}$ sem./2004. São Paulo: Instituto de Física da Universidade de São Paulo, 2004.

6 FEYNMAN, Richard P. Física em seis lições. Trad. de Ivo Korytowski. Rio de Janeiro: Ediouro, 2001, p. 89-90.

7 MENEZES, op. cit., p. 14.

8 LÉVY-LEBLOND, Jean-Marc. Science's fiction. Hampshire: Nature, v. 413, n. 573, 2001.

9 QUEIRÓ, João Filipe. Ciência islâmica: alguns aspectos de sua história. Oeiras: Expresso (Revista), p. 119, 2001. 
tocar em outro aspecto tão importante quanto a nova matemática: as normas experimentais como normas de provas. ${ }^{10}$

Adiante, podemos dizer que a partir do período histórico conhecido como Renascimento europeu, entre os séculos XIV e XVII, pós evolução científica árabe, e abusando de recursos da filosofia, da linguagem, da astronomia e da matemática, foi que se permitiu a diversos pesquisadores compreender alguns fenômenos de uma maneira mais apurada do que anteriormente: Copérnico, Brahe, Kepler, Galileu e Newton, para citar alguns.

Essa enxurrada de novas interpretações e conclusões durante o Renascimento formaram o que Thomas Kuhn chama de Revolução Copernicana. ${ }^{11}$ Dessa revolução, áreas do pensamento até então independentes, como a física dos graves (que estudava o movimento dos corpos na superfície do planeta) e a astronomia (que estudava o movimento dos corpos celestes) tornaram-se uma só, e a divisão concreta entre Terra e Céu, que perdurou tantos séculos apesar do desenvolvimento conceitual desde a Antiguidade, foi-se esvaindo e permitindo que olhássemos para fenômenos celestes e terrestres como sendo de mesma natureza, ou seja, sendo regidos por leis físicas comuns.

A física, então, com esse caráter de buscar identidade na diversidade e permanência na fluidez, permite muitas vezes que agreguemos áreas do conhecimento até então distintas em uma única. O professor Menezes descreve essa dinâmica, a qual chama de "aventura do espírito”, como uma possível arquitetura da física, como mostrado na figura 1.

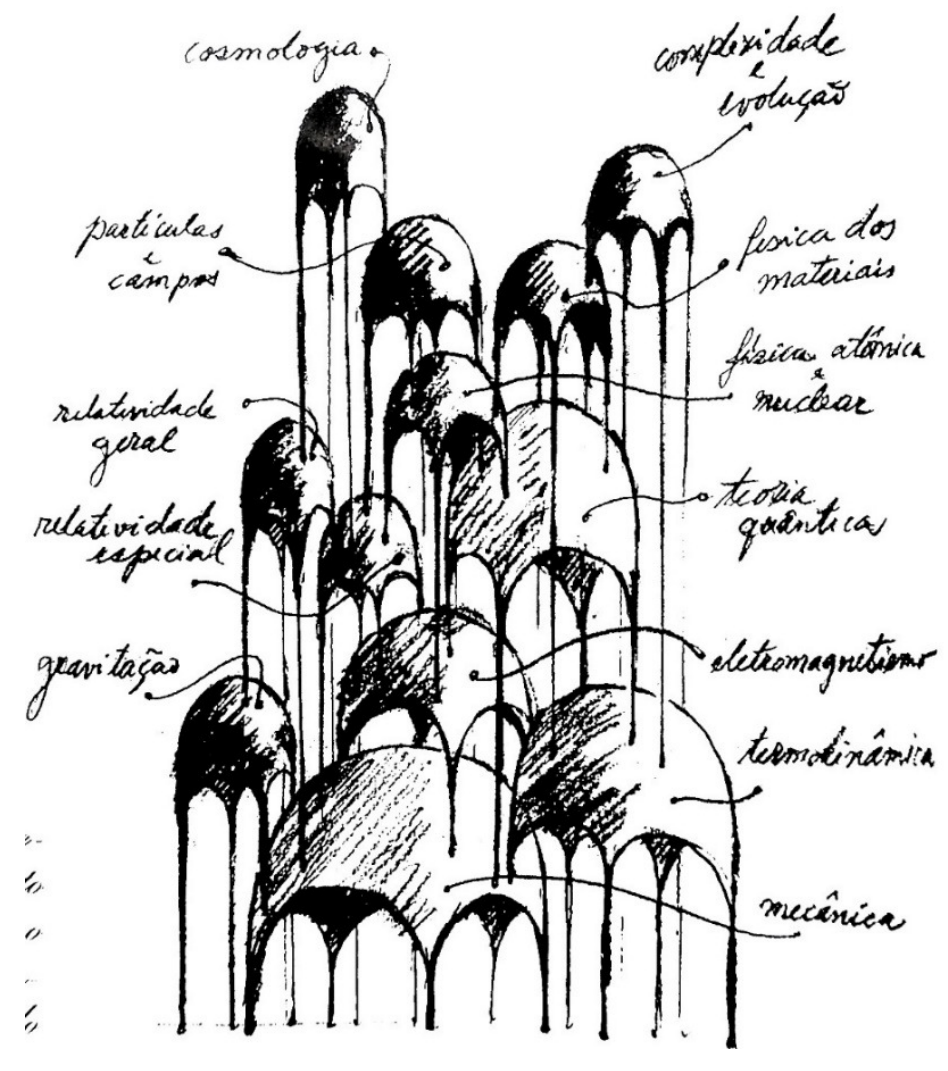

Figura 1. Arquitetura da física. ${ }^{12}$

10 RASHED, Roshdi. Modernité classique et science arabe. (Trad. Aida R. Hanania e Jean Lauand). Paris: C. Goldstein et J. Ritter (org.), Mathématiques en Europe. Ed. MSH, p. 68-81, 1996. Disponível em: http:// hottopos.com/collat6/roshdi2.htm, acessado em 12 de novembro de 2015.

11 KUHN, Thomas S. A estrutura das revoluções cientificas. São Paulo: Ed. Perspectiva, 1975.

12 MENEZES, op. cit., p. 32. 
A figura simplifica o modo como as unificações das interpretações das leis da natureza vêm sendo construídas partindo, na base: das teorias clássicas da mecânica, da gravitação e da termodinâmica (da antiguidade ao século XIX); seguindo pelo conhecimento do eletromagnetismo e da relatividade (entre os séculos XIX e XX); alcançando patamares mais altos, com relação ao tempo e à complexidade dos conceitos, com a relatividade geral, a teoria quântica e a física atômica e nuclear (do início do século XX); e a física de partículas e de campos, a física dos materiais, a cosmologia, a complexidade e a evolução (da metade do século XX para cá).

Durante essa evolução (temporal) da física, não linear, todas as outras áreas da ciência também evoluíram e a física parece viver num paradoxo: internamente, a física está extremamente mais complexa, utilizando recursos de outras áreas, como a matemática, a filosofia e a história, que também estão muito mais complexas, e empregando recursos da tecnologia, que também atingiu patamares jamais imaginados há dois ou três séculos; por outro lado, a grande busca da física no último século é a unificação das leis e das interpretações, ou seja, busca-se a identidade e a unidade num mar cada vez mais complexo de teorias e leis.

Por tudo isso, é interessante discutirmos algumas razões pelas quais os "mistérios talvez se tornem cada vez maiores". Ou, voltando o olhar para a didática das ciências, é possível também perguntar: por que não podemos ensinar física linearmente? Do básico ao complexo, em cada tema? Para Feynman, isso ocorre pois "ainda não conhecemos todas as leis básicas: existe uma região em expansão de ignorância" e, além disso, "tudo que conhecemos é apenas algum tipo de aproximação, pois sabemos que não conhecemos todas as leis ainda" $(i d e m) .{ }^{13}$

Deste contexto, do qual apresentamos uma percepção de que o homem conhece grande parte da história da física, conhece suas limitações e define novos conceitos e leis no decorrer do tempo, faz-se necessário o estudo de como tem sido feita a física, como são definidas suas leis e regras gerais, quem construiu e quem constrói esta ciência, ou seja, quais as "regras do jogo". Este estudo, ora chamado de Filosofia da Ciência, ora de Epistemologia, teve alto desenvolvimento durante o século XX e tem como nomes cada vez mais populares as figuras de Bachelard, Popper, Feyerabend, Lakatos e Kuhn, suscitando a discussão sobre o " fazer" científico e pensando a física no contexto da totalidade da população. ${ }^{14}$

Apesar do fato de a física ser uma só, defini-la enquanto ciência não é tarefa unânime e, nos parágrafos anteriores, tentou-se apresentar uma possível forma de enxergá-la. Contudo, parece-nos necessário discutir o "fazer" da física, pois essa ação, ou esse conjunto de ações, é entendida de formas muito diferentes; por um lado, porque a comunidade dos físicos, ou a sua tribo, na análise crítica do antropólogo e sociólogo da ciência Bruno Latour, pertence a um contexto espaço-temporal (político-sócio-cultural) muito bem definido e, por outro, porque cada físico tem uma visão de mundo muito peculiar. ${ }^{15}$ Isso indica que há um aspecto coletivo na construção da ciência, envolvendo o local, a época, a instituição, a nação e a educação, do qual o cientista em questão participa ou participou, e há um aspecto individual que diz respeito aos desejos, à visão de mundo, às crenças e às condições psicológicas de cada um. Ou seja, a construção e a apropriação do que é isto que chamamos física se deve à cultura, como conjunto de valores materiais e espirituais criados pela humanidade, no curso de sua história. ${ }^{16}$

13 FEYNMAN, op. cit., p. 36.

14 ZANETIC, João. Física também é cultura. Tese de doutoramento. São Paulo: Faculdade de Educação da Universidade de São Paulo, 1989.

15 LATOUR, Bruno. Ciência em ação: como seguir cientistas e engenheiros sociedade afora. São Paulo: Ed. Unesp, 2000.

16 SODRÉ, Nelson Werneck. Sintese de história da cultura brasileira. Rio de Janeiro: Ed. Civilização Brasileira, 4a. ed., 1976, p. 3-4. 
"A História da Ciência mostra assim que ideias aparentemente incorretas são posteriormente válidas e que haviam correspondido a intuições profundas. Vemos então que a evolução dos conceitos da Física é algo paradoxal e extremamente interessante porque não é processo retilíneo, mas um verdadeiro ziguezague. Contudo, a ciência vai progredindo, cada vez descobrindo novas verdades. Mesmo quando se volta para uma ideia que já existia antes, não se volta do mesmo modo com que ela havia sido formulada anteriormente". ${ }^{17}$

No propósito de interpretarmos o fazer da ciência como uma prática cultural, ou seja, que está alocada num contexto espaço-temporal específico e que segue evoluindo conjuntamente à evolução geral do ser humano histórico, utilizarei a análise kuhniana como foco principal.

$\mathrm{Na}$ epistemologia de Kuhn, a ciência, enquanto atividade humana, pode ser vista como um apanhado de processos que são construídos ao longo do tempo no decorrer do desenvolvimento humano e que parece seguir uma série de movimentos mais ou menos possíveis de detectar na posteridade, ou seja, há uma sequência de acontecimentos que podem ser observados no estudo da história e da evolução dos fatos científicos, mas que são difíceis de se identificar no presente, com especial atenção aos momentos de revolução científica.

Para que possamos compreender uma das razões que levaram ao desenvolvimento desta forma de ver a ciência e a sua evolução, podemos notar que as teorias científicas atualmente em voga surgiram após transformações, aperfeiçoamentos ou abandonos de outras ideias e teorias muito bem fundamentadas. O que significa que, em outros tempos, a humanidade (e a tão restrita comunidade científica) já conviveu, em plena concordância, com teorias que descreviam, anteviam ou previam situações e fenômenos naturais com tamanha precisão que perduraram muitas décadas, às vezes séculos e, menos comumente, milênios. Muitas dessas teorias ou ideias são hoje tidas como mitos ou equívocos e não como ciência. ${ }^{18}$

Neste contexto, a evolução das ideias científicas segue fases como: a) pré-paradigmática, onde há competição entre teorias candidatas a paradigma; b) definição em favor de uma das teorias, caracterizada pela ocorrência da ciência normal a partir da procura de solução de quebra-cabeças; c) articulação do paradigma, na tentativa de aproximar novos fatos e as teorias; $d$ ) ocorrência de anomalias ou descobertas não previstas pelo paradigma vigente; e) crise gerada eventualmente pelas anomalias, trazendo à tona fatores não necessariamente "científicos"; f) propostas de novas teorias e o comprometimento com uma delas por uma fração da comunidade científica (nova visão de mundo com possível revolução científica); $g$ ) aceitação da nova teoria pela comunidade científica, reiniciando um novo ciclo de ciência normal.

É possível percebermos, portanto, que a atividade científica não é e nunca foi formada por uma sequência linear ou pouco turbulenta de acumulação de saberes e conhecimentos. Em períodos por vezes longos, durando séculos, a humanidade e a comunidade científica consideram uma série de processos como sendo ditos "científicos" e que se tornam "mitos" quando vistos a partir do levantamento histórico.

A ideia do espaço vazio, do vácuo, do nada ou do espaço plenamente preenchido por matéria vem sendo discutida há milênios, ainda sem aceitação plena, sendo que: ora é aceita a concepção de espaço preenchido enquanto espaço humano, diferenciando do espaço dito

17 SCHENBERG apudZANETIC, 1989, op. cit., p. 114-115.

18 KUHN, op. cit., 1975. Para um detalhamento maior da epistemologia kuhniana, ver ZANETIC, op. cit., 1989. 
divino; ora o espaço vazio é tido como infinito; ora o nada é definido como limitador do Universo, entre várias outras concepções conflitantes. A essas concepções associamos as religiões, as artes, a filosofia, a metafísica e a vida cotidiana. A cultura, como parte fundamental da construção humana da realidade material, guia e é guiada pela ciência, num processo dialético onde o homem possui papel central.

Sendo assim, a ciência e, especialmente, a física, vem sendo construída ao longo dos séculos, não de forma isolada dentro dos laboratórios e centros acadêmicos, mas como parte de toda a construção de realidade material da humanidade, partilhando visões de mundo, contextos políticos, articulações, combinações e colonizações, que permitiram a aceitação, num dado instante, de determinados conceitos e teorias (paradigmas) e de outras teorias, em outros momentos.

Portanto, a interpretação do senso comum, ingênua e alienada, de que a ciência poderia ser neutra, no sentido político, filosófico, artístico e religioso, não condiz com a observação atenta da história da humanidade. Sua divulgação e propagação ocorrem quase que exclusivamente a partir de cursos de formação de cientistas e da produção e divulgação de materiais didáticos, ambos regulamentados pelo Estado, direcionados para públicos específicos e com fins geralmente bastantes estabelecidos.

A noção de que a ciência não é cumulativa e de que é construída como parte do sistema político, dos padrões religiosos, das manifestações artísticas e do pensamento filosófico e metafísico necessita, como defesa nossa, ser cada vez mais trabalhada nas escolas de base. Apesar do Brasil atualmente figurar no cenário mundial como uma das grandes economias do mundo capitalista, o incentivo à pesquisa científica e ao desenvolvimento tecnológico desde a educação básica ainda é muito baixo.

\section{A Física na escola básica: alguns dados relevantes}

Para avaliar como a física tem sido ensinada nas escolas brasileiras e para estabelecer relações com a história da física, analisamos alguns dados apresentados em questionários respondidos por professores da rede pública e recortados para este trabalho. Vale notar que, dada a limitação do nosso recorte, o estudo não é estatístico e nem tampouco generalizável: mais apropriadamente, deve ser considerado como um estudo de caso. ${ }^{19}$

Selecionamos in loco dezesseis professores de física, em atividade regular no ensino médio, em escolas públicas da cidade de São Paulo. ${ }^{20} \mathrm{O}$ trabalho foi dividido em três blocos, a saber: a) organização do trabalho docente; $b$ ) física enquanto ciência e cultura; c) a pesquisa em ensino de física. Para o presente texto, focamos nos blocos b) e c), com o objetivo de compreender como o professor responsável pela disciplina de física interpreta a natureza da ciência, seu fazer e seu desenvolvimento histórico, como ele avalia a compreensão de seus alunos acerca do fazer científico e da estrutura da ciência e como ele tem trabalhado a física em sala de aula.

19 CESAR, Ana Maria Roux Valentini Coelho. Método do Estudo do Caso (Case Studies) ou Método do Caso (Teaching Cases)? Uma análise dos dois métodos no ensino e pesquisa em administração. São Paulo: Universidade Presbiteriana Mackenzie, 2005.

Disponível em: http://www.mackenzie.br/fileadmin/Graduacao/CCSA/remac/jul_dez_05/06.pdf . Acessado em 23/11/2015.

20 Ver PUGLIESE, R. M., op. cit. (2016) para mais informações. Cabe ressaltar que 50\% desses professores também atuam na rede privada de ensino. 
Nos gráficos a seguir, são apresentadas as respostas dos professores a algumas questões, após fazemos uma análise dos dados. ${ }^{21}$ As duas primeiras questões tratam das condições que se devem oferecer aos estudantes para a apropriação da cultura científica e quais têm sido colocadas em prática.

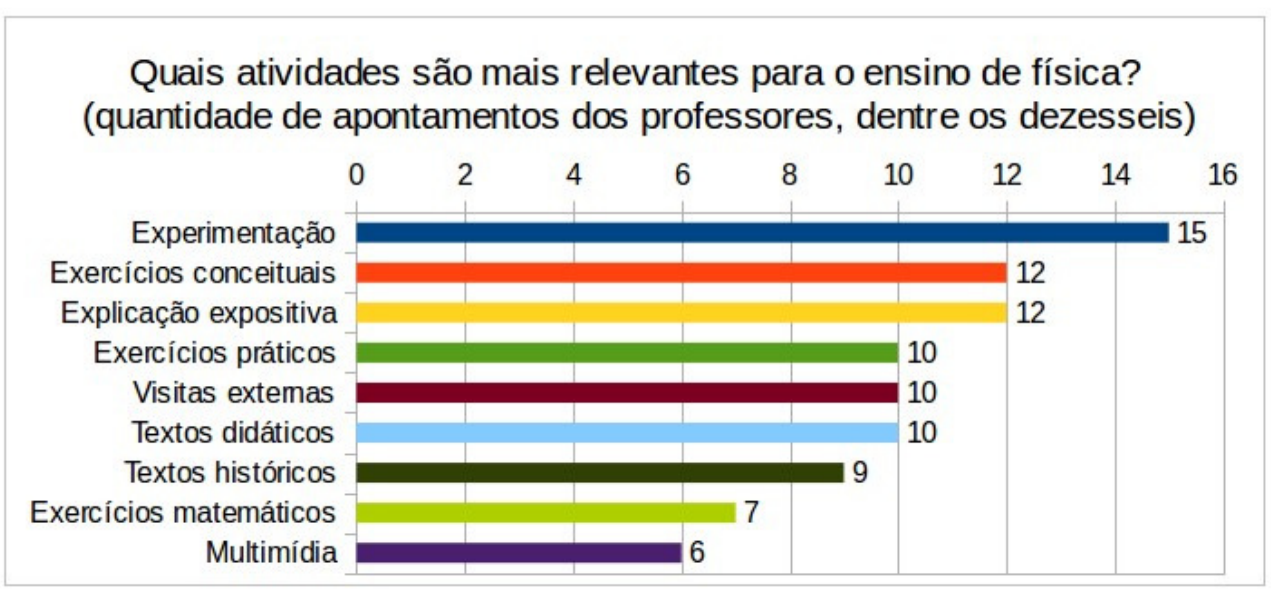

Gráfico 1: Atividades mais relevantes para o ensino de física.

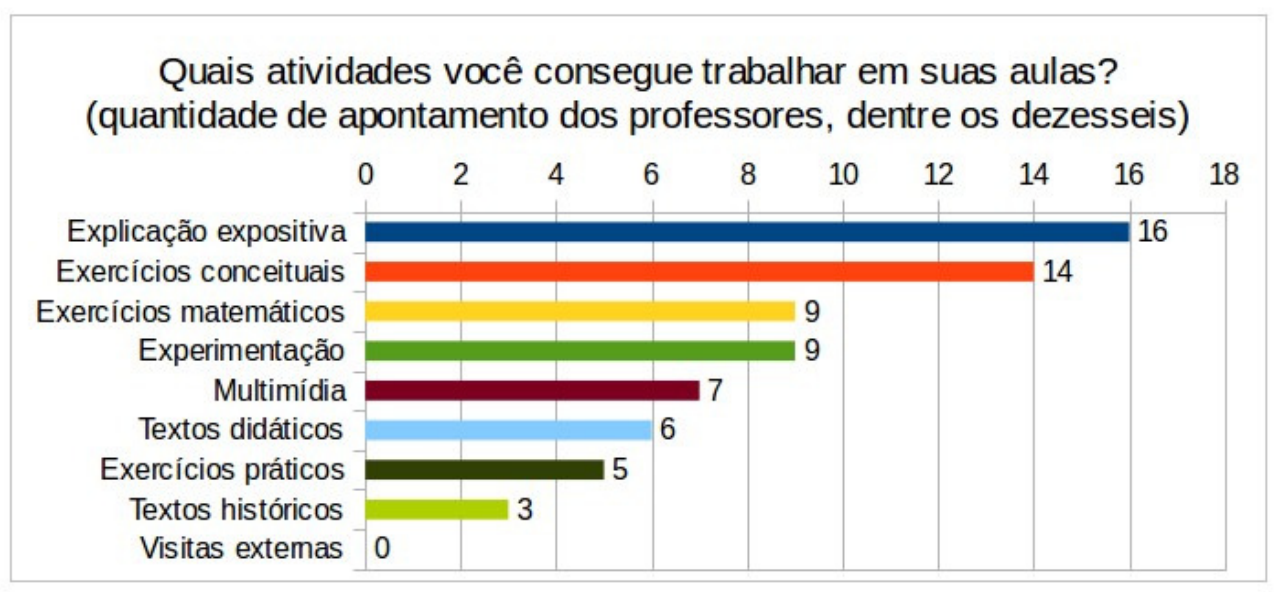

Gráfico 2: Atividades trabalhadas cotidianamente no ensino de física.

A questão seguinte serviu para avaliar a satisfação quanto ao conhecimento físico apropriado pelos estudantes, após o trabalho do professor de física. A pergunta era: Você sente que, ao final do ensino médio, seus alunos aprenderam o que é, onde está e como se faz física?

21 Cabe lembrar que as opções de respostas aqui plotadas estão resumidas quanto da expressão original. Por exemplo, a opção Experimentação no questionário aparecia como Experimentação (laboratório, demonstração ou investigação). Para mais detalhes, ver PUGLIESE, R. M., op. cit. (2016). 


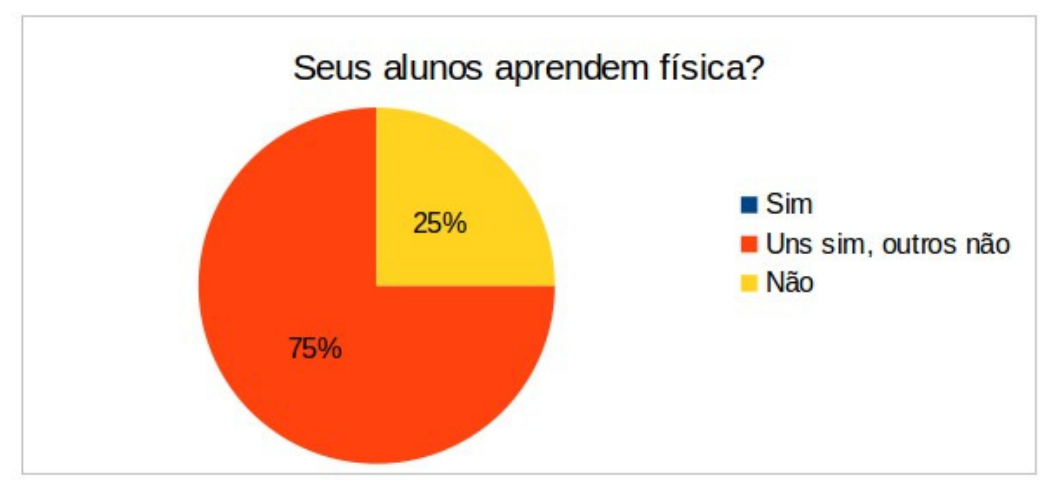

Gráfico 3: Percepção da aprendizagem de física pelos alunos.

Para avaliar a satisfação do professor com sua formação e sua noção de continuidade da ciência, enquanto produção não acabada de conhecimento, tivemos a seguinte questão: Você acredita que, para ser um bom professor de física, lecionando no ensino médio, basta o curso de licenciatura em fisica?

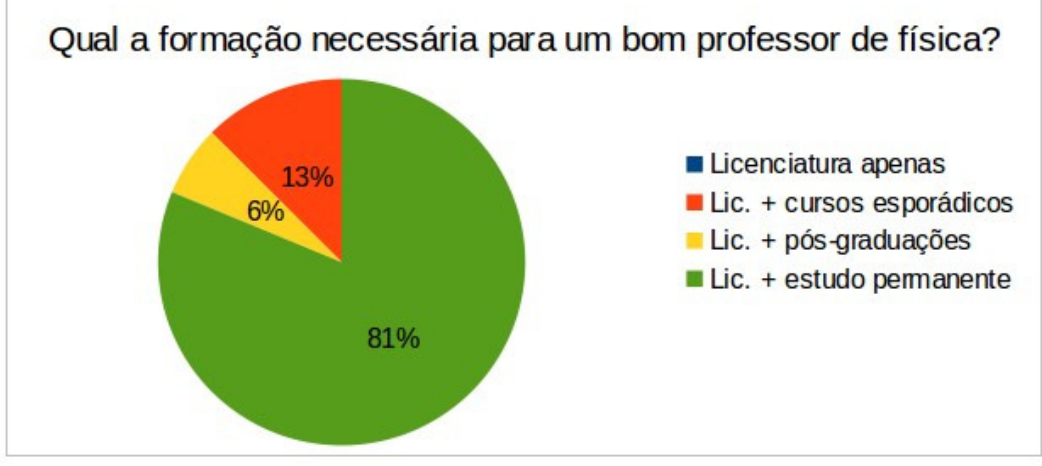

Gráfico 4: Formação necessária para um bom professor de física.

Voltando o olhar para o conteúdo curricular de física no ensino médio, a partir de temas sugeridos nos $\mathrm{PCN}+22$ e nas $\mathrm{OCN}^{23}$ e dos resultados da pesquisa em ensino de física, esta questão objetiva fazer um levantamento dos assuntos que têm sido ensinados. Foram sugeridos 26 temas da física que permeiam as discussões nos projetos de pesquisa em ensino de física, além de um espaço para outro possível tema.

22 MEC. PCN+ Ensino Médio - Orientações Educacionais Complementares aos Parâmetros Curriculares Nacionais. Brasília: Ministério da Educação, 2002.

23 MEC. Orientações Curriculares para o Ensino Médio. Brasília: Ministério da Educação, 2006. 
Khronos, Revista de História da Ciência

ISSN 2447-2158 - no 4, agosto 2017

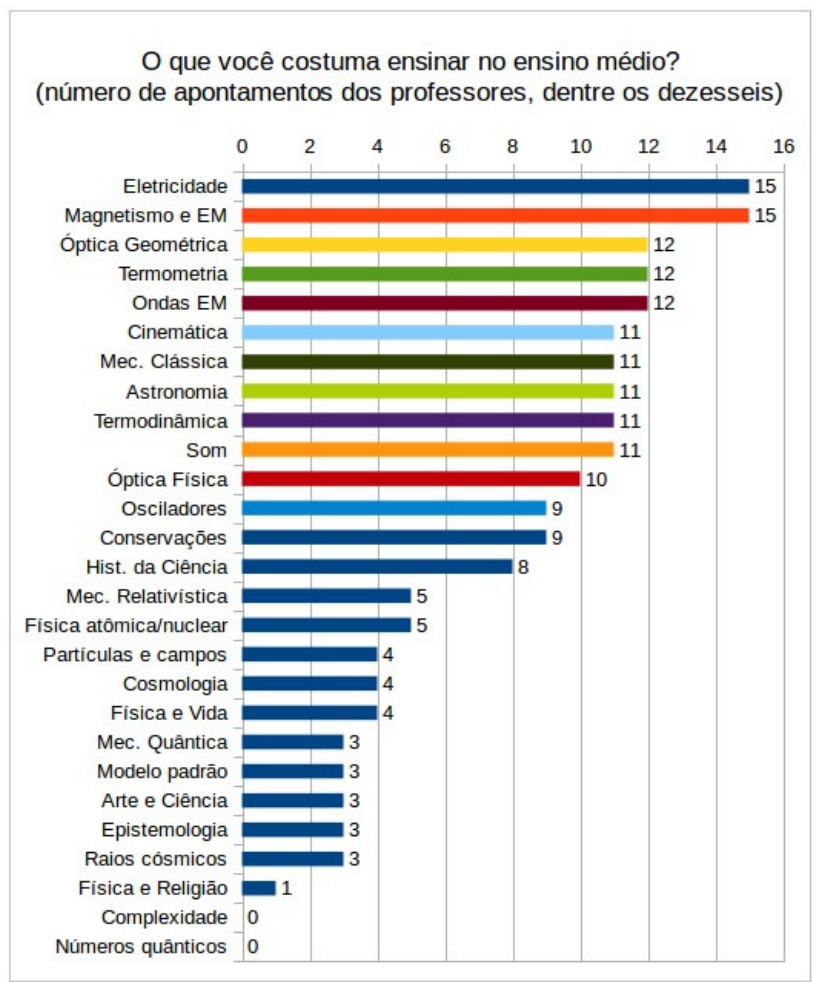

Gráfico 5: Temas mais ensinados no ensino médio.

Na próxima seção, são apresentadas as correlações entre os dados e analisado como podem estar presentes (ou ausentes) os elementos da história da física, na física que é ensinada na escola básica.

\section{A Física na escola e a Física enquanto ciência: incoerências}

Observando os dados acima, podemos afirmar que: a) as aulas são quase que exclusivamente expositivas de conteúdo; b) as atividades realizadas com os alunos são pautadas em resoluções de exercícios conceituais e matemáticos, com experimentação demonstrativa; c) quase a totalidade dos professores considera necessário a experimentação em aulas de física; $d$ ) a maioria também considera necessário a realização de visitas externas e de exercícios práticosexperimentais, a leitura de textos didáticos e histórico-científicos.

Apesar das reformas documentais, dos textos produzidos para formação continuada e mesmo dos parâmetros curriculares nacionais e seus complementos, oferecendo propostas bastante inovadoras, é fácil perceber que grandes sugestões reformistas (como as do PCN+e das OCN) ou implementações verticais (como as do programa São Paulo faz Escola) ${ }^{24}$ não interferem significativamente na realidade da sala de aula, mesmo após muitos anos. "As soluções educacionais formais, mesmo algumas das maiores, e mesmo quando são sacramentadas pela

24 Programa de reforma e centralização curricular do Governo do Estado de São Paulo, constituído de apostilas (cadernos) distribuídas aos alunos, professores e gestores, com conteúdo seccionado por aulas distribuídas ao longo do ano letivo. Iniciado em 2008. 
lei, podem ser completamente invertidas, desde que a lógica do capital permaneça intacta como quadro de referências orientador da sociedade" 25 . As relações sociais são espetaculares ${ }^{26}$, pautadas pela aparência.

Nenhum professor, dentre os entrevistados, afirma que seus alunos, em geral, aprendem física, ao passo que todos eles afirmaram que apenas a formação inicial, para a prática docente, não basta. Eles sabem que não é suficiente e que o efetivo trabalho docente está pautado no estudo permanente frente as transformações científicas e sociais, apontando vontade de estudar sempre, como parte do trabalho.

Quando voltamos o olhar ao conteúdo trabalhado em sala de aula, temos que os 10 temas mais ensinados são os da Física Clássica, desenvolvida até o final do século XIX, e que os 10 temas menos ensinados são os da Física Moderna, desenvolvida no século XX. Os temas ensinados nessas aulas são os tradicionais temas da chamada Física Clássica e presentes em todos os livros didáticos, apostilas, cadernos e processos seletivos, como os vestibulares e o ENEM. Vale notar que, como a idade média dos professores aqui investigados é de 37 anos, sua formação universitária se deu no final do século XX ou início do século XXI.

Em contrapartida, o cotidiano dos habitantes (professores, estudantes e comunidade) de uma cidade como São Paulo, é recheado de tecnologia desenvolvida com a chamada Física Moderna, construída ao longo do século XX - como os televisores, computadores e celulares, os quais utilizam telas (display) de LED, ${ }^{27}$ componentes eletrônicos como CI e transistores ${ }^{28}$ - e se comunicam via ondas elétricas ou eletromagnéticas digitais, ${ }^{29}$ com especial atenção à internet. Para além destes aparelhos, tão presentes em nossas vidas, há ainda as portas automáticas que se abrem quando nos aproximamos, ${ }^{30}$ os LASERs, ${ }^{31}$ viagens espaciais, Big Bang, satélites, e tantos outros possíveis exemplos cotidianos que nasceram da Física Moderna.

Dentro dessas condições, há uma tentativa vã de se ensinar física como se esta fosse construída de forma linear: primeiramente, tenta-se ensinar a Física Clássica para, se possível, alcançar o estudo da Física Moderna (que não se alcança, como vimos). Tenta-se ensinar os conceitos para, se possível, fazer experimentações (que não são feitas, também como vimos). É o oposto da física, enquanto ciência e cultura. Essa é uma atitude impensada, não reflexiva, que remete ao senso comum e à manutenção da ordem de classe social. Não se faz investigação experimental e, portanto, não há erros, apenas as certezas dos livros didáticos. Não há revolução científica, não há incertezas, há apenas condicionamento ético.

Esse trabalho docente, estritamente concentrado na atuação em sala de aula, com baixo salário e pouco ou nenhum intervalo de tempo para investigações, reflexões ou preparo de atividades inovadoras, reproduz as conhecidas e tão criticadas aulas tradicionais: giz e lousa, apesar de a quase totalidade dos professores possuírem diploma de cursos de pós-graduação e apresentarem conhecimento razoável de temas da PEF, o que indica um mínimo contato com metodologias inovadoras, propostas de investigação, a necessidade da inserção da Física Moderna no ensino básico, etc. ${ }^{32}$

${ }^{25}$ MÉSZÁROS, István. A educação para além do capital. São Paulo, Boitempo. 2008.

${ }^{26}$ DEBORD, G. A Sociedade do espetáculo e Comentários sobre a sociedade do espetáculo, Ed. Contraponto, Rio de Janeiro, 1997.

27 Diodos emissores de luz (Light Emitting Diode), desenvolvidos na década de 1960, a partir de fenômenos conhecidos na década de 1910.

28 CI (circuitos integrados) e transistores: componentes desenvolvidos na década de 1950.

29 Desenvolvidas na década de 1970, a partir de conceitos da Física Quântica (início do século XX).

30 Com sensores fotoelétricos, conceitos da década de 1900.

31 LASER (Light Amplification by Stimulated Emission of Radiation): conceitos de 1905 e construção em 1950.

32 PUGLIESE, R.M., op. cit. (2016). 
Para além dos dados supracitados, vale incluir neste texto alguns aspectos presentes em pesquisa anterior, acerca do conteúdo curricular presente em materiais didáticos de física. ${ }^{33}$ Com um pouco de atenção, é possível encontrar dezenas de propostas de atividades experimentais, exemplos práticos ou exercícios e problemas teóricos que não são aplicáveis no mundo real (fora dos livros didáticos) e não condizem com a física construída nos últimos séculos.

Há casos em que se discute conceitos sobre luz e som, por exemplo, com diversas situações imaginadas e apresentadas como experimentais, mas que não são reais e nem podem ser realizáveis, pois não correspondem à natureza física observável. Mais absurdo ainda é que a grande parte das propostas ditas experimentais (ou como "faça você mesmo"), poderiam ser efetivamente experimentadas e verificadas, quanto de suas limitações ou equívocos epistemológicos.

Percebe-se que é necessário investir na experimentação, na inserção da Física Moderna no cotidiano escolar e na atuação do professor como investigador. O ensino de física, sua forma e conteúdo curricular, precisa de mudanças bruscas: os professores desejam inserir mais tópicos de física moderna, desejam fazer mais experimentações, desejam visitar centros de ciências e museus, além de desejarem que seus alunos leiam mais (textos didáticos e históricos). Em sua prática, afirmam escolher qual material didático será adotado, mas mostram que seus alunos não leem. Afirmam que estudam em cursos de pós-graduação e conhecem os temas da PEF, mas demonstram que ensinam os tradicionais tópicos da Física Clássica, em aulas quase que exclusivamente expositivas. É preciso que trabalhem mais coletivamente e estudem mais individualmente, o que só será possível com mais tempo disponível para tal na referida unidade escolar, ou seja, com mudanças estruturais nas condições de trabalho.

\section{Considerações finais}

Enquanto a história da física apresenta uma ciência não linear e tampouco cumulativa, no sentido objetivo, o ensino de física nas escolas básicas demonstra características, sobretudo na análise do livro didático, de que os cientistas vão contribuindo com a construção da ciência de forma linear e cronologicamente cumulativa.

O currículo concreto, aquele que efetivamente se faz na escola (especialmente no Ensino Médio, onde a física aparece como componente curricular independente e obrigatória), tem a prática de iniciar com a física desenvolvida no século XVI e culminar na física desenvolvida no século XIX (período denominado Física Clássica), desprezando a Física Moderna e descontextualizando a parceria ciência-tecnologia presente no cotidiano da população.

A epistemologia, a história e a sociologia da ciência mostram que a construção das teorias e a validação da argumentação teórica fazem parte de um arcabouço de interlocuções, acordos e entraves político-econômicos que legitimam ou desqualificam ideias. No entanto, a física apresentada como apolítica e livre de contexto político nas escolas tem, inclusive, perdido crédito enquanto matéria necessária de estudo obrigatório, como apoiado por grande parcela da população, convencida da boa vontade das recentes reformas.

A experimentação, peça chave na construção de toda e qualquer teoria científica nos últimos séculos, não está presente nas escolas, levando à falácia ideológica de que o erro e as incertezas não estão presentes no cotidiano do fazer ciência, como a história mostra. O diálogo

33 PUGLIESE, R.M., op. cit. (2011). 
A História da Física e a Física Escolar:

incoerências entre a ciência e o ensino

homem-natureza está ausente do ensino de física, reforçando a degradação da dúvida como mote no desenvolvimento científico e tecnológico. 